\title{
Remote Sensing in Archaeology
}

\author{
By J. L. van GENDEREN
}

Remote sensing can assist the archaeologist in the following ways:

(i) In the discovery of previously unknown sites. This has been the most spectacular use made of aerial techniques. There are many cases where low level oblique photography, using mainly straightforward black and white panchromatic film, has resulted in the discovery of a variety of archaeological sites. ${ }^{1}$

(ii) Vertical aerial photographs, because of their geometric properties, can be used as base maps on which one can plot the relevant archaeological details. They are an excellent means of checking ground surveys, saving much costly time in the field. When viewed stereoscopically, accurate topographic maps can be drawn from the photographs.

(iii) Because of the choice in flying height and focal length of the camera, both vertical and oblique aerial photographs enable larger areas to be studied, so that patterns not easily comprehended at ground level may be evaluated. Another advantage of taking smaller scale photographs in addition to the large-scale detailed site photographs is that the synoptic view thus obtained allows one to determine the whole set of environmental parameters which may have played a role in the establishment of the site in a particular location.

There is, therefore, a marked difference between detection and interpretation using aerial photographs. Most of the work carried out to date has been concerned with the discovery, location and identification of archaeological sites, but far more work needs to be done to interpret or explain these sites. Remote sensing can contribute significantly to this task. ${ }^{2}$

The fundamental image characteristics which the photo interpreter uses for identification and analysis are tone, texture, structure, pattern, shape, size, shadow, orientation, relief, lineations and associated features. All of these image characteristics need to be employed when interpreting remote sensing imagery for archaeology. In photographic terms, the common factor which constitutes the whole image is variation in tone or density, thereby making possible the perception of the other image characteristics.

1 R. Agache, 'Recherche des moments favorables à la mise en évidence des vestiges archéologiques arasés par l'agriculture dans le nord de la France', International Arcbives of Pbotogrammetry: Transactions of the and International Symposium on Photo Interpretation (Paris, 1966), 9-18; M. W. Beresford and J. K. S. St Joseph, Medieval England: an Aerial Survey (Cambridge, 1958), passim; R. Chevallier, 'Bibliographie des applications archéologiques de la photographie aérienne', Bulletin d'Arcbéologie Marocaine, 4 (1960), 106-56.
2 G. J. Gumerman and T. R. Lyons, "Archaeological methodology and remote sensing', Science, 172 (1971), 126-32; R. M. Newcomb, 'An example of the applicability of remote sensing: historical geography', Geoforum, 2 (1970), 89-92; R. S. Solecki, et al., 'Photo interpretation in archaeology', Manual of Pbotograpbic Interpretation (American Society of Photogrammetry, Washington, 1960), 717-33. 
Tonal variations, therefore, are very important. The use of these image characteristics enables one to proceed from the step of 'detection' to identification, recognition, interpretation and classification.

One method which has been devised to cope with this procedure is the use of air photo keys. ${ }^{3}$ Some of the reasons proposed for using keys are that they serve as valuable short cuts in interpretation, especially if highly trained personnel are not available, and that they assist greatly in the training or education of archaeological photo interpreters. However, a far more important reason supporting the use of air photo interpretation keys, illustrated with either single oblique or stereo photography, is that there is an urgent need to analyse and process the enormous quantity of photography already in existence, for the preliminary isolation of features. The existence of a large number of known archaeological sites provides the 'user' 'with an ever increasing interpretative work load. This, together with the fact that many historical sites are being destroyed by new housing estates, expanding industrial development, etc., shows an acute need for site classification and evaluation, as a framework for subsequent site reservation and data inputs for the setting up and testing of hypotheses on the significance of sites. If good keys were to be devised by those with the greatest experience and expertise in photo interpretation and site classification, then other interested persons could contribute significantly to the burgeoning problems of identification, location and classification of the sites contained in the many images needing analysis, if progress is to be made in our understanding of the sites. Tables I and 2 provide examples of two types of key devised by Newcomb.

TABLE I. A selective key for the historical interpretations of aerial photographs

\section{Category}

I. Areal Features

2. Linear Features

3. Focal Features

4. Point Features

5. Complex Features

\section{Assemblage of Features and Illustrations}

'Grain' or pattern of the land surface, consisting here mostly of agricultural features. e.g., Celtic Fields, Lynchets.

Travelling earthworks, boundaries, alignments, and transportation lines. e.g., Roman Road, Wansdyke, the Old Bath Road, the Kennet and Avon Canal.

Ritual centres, settlements, habitation complexes, and communications junctions. e.g., the Avebury Complex, Windmill Hill.

A great range of possibilities, including monuments, small enclosures, and isolated buildings. e.g., Silbury Hill, Knap Hill Fort.

Overlaps in position or in usage characterize these, and usually reflect origins at different times. Includes overlapping land uses, and military or political frontiers. e.g., overlap (a) between Roman Road and Ridgeway, and (b) Roman Road and Wansdyke; the Avebury Circle, occupied since Bronze Age.

${ }^{3}$ R. M. Newcomb, 'Two keys for the historical interpretation of aerial photographs', Californian Geographer, $7(1966), 37-47$. 
TABLE 2. A dichotomous elimination key for the interpretation of enclosed features of ancient British field types

I. SIZE of Enclosed Area large

II. SIZE of Enclosed Area small

A. SHAPE of Area irregular

1. Irregular but rectilinear

2. Irregular but long and narrow

B. SHAPE of Area regular

I. PATTERN or Relationship with other Enclosures

2. PAT'TERN or Relationship with other Enclosures

(a) CULTIVATION MARKS

absent, although may have

slight scratching marks of

cultivation, usually 2 sets

criss-cross

(b) CULTIVATION MARKS

present, banks and hollows or ridge and furrow in elongated strips bundled into rectangular groupings. agricultural enclosures such as ranch boundaries, cattle corrals, pastoral enclosures, and estate boundaries

corn plots of Neolithic and Bronze Age strip-lynchets, lynchets, terraces

Roman fields, e.g., centuriation.

Celtic Fields

Ridge and furrow

However, when using keys in this way, one must bear in mind some of the limitations of such an approach, as very many special cases exist among historic features, and categories tend to grade into one another. Keys are only valid on a regional basis, different keys being necessary for different archaeological areas. Also, the diversity of features to be handled may limit the usefulness of air photo keys.

When using aerial photographs, the archaeologist should possess an understanding both of the processes at work in the production of marks at ground level in the field and the marks produced upon the photographic film in addition to his archaeological knowledge.

The sites detected by aerial photography fall into two categories: sites directly visible (by virtue of some vestige of relief) and sites indirectly visible. Because of the usually low scale of relief, directly visible sites depend upon some form of enhancement to ease their discovery and interpretation. The main method of enhancement is the use of shadow marks, whereby features are shown by the contrast in tone between shadows, normal light and highlight (shine marks); other methods are snow marks and flood 
marks. It is not proposed to enter into the details of shadow sites since these have been discussed extensively in the literature. ${ }^{4}$

However, several new developments need to be taken into consideration. Up to the present, very little use has been made by aero-archaeologists of ordinary black and white infrared film, which is readily available in all formats. The difference in cost between this film and the conventional black and white panchromatic film is negligible, and cannot therefore be the reason for the very restricted use made of this type of film to date. Possibly those concerned have not been fully aware of the properties of infrared film. With infrared film, the blue end of the spectrum is effectively cut off by filters and replaced by the longer infrared wavelengths (Fig. 1). Thus infrared film has superior haze-penetration capabilities and it can be used under conditions where normal panchromatic film would not provide good quality pictures. This property of infrared film

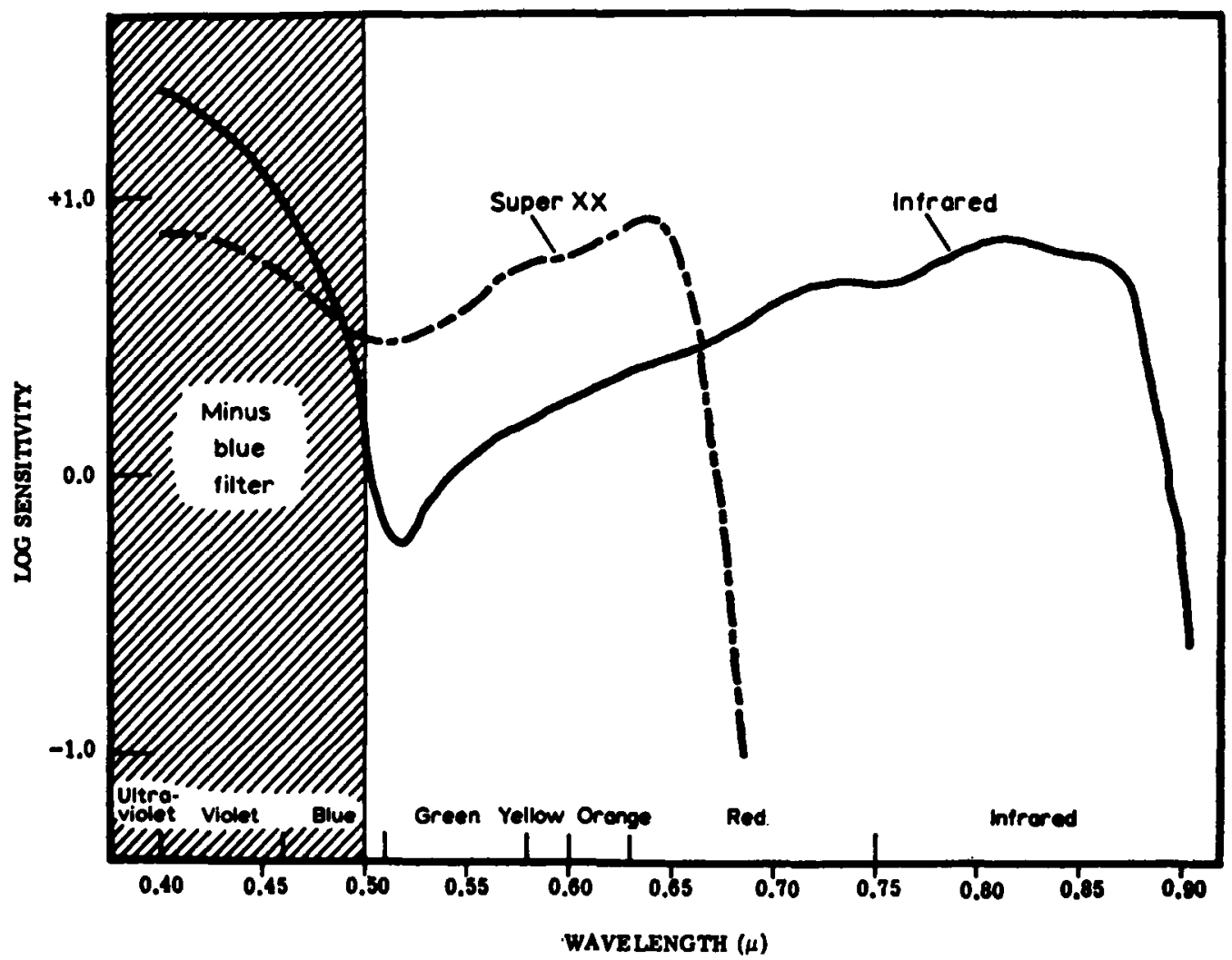

Fig. 1. Spectral sensitivity of Kodak Infrared Aerographic film and Kodak Super XX aerographic film at various wavelengths. Note the effect of the minus blue filter and the cut-off wavelengths for both films

4D. M. Reeves, 'Aerial photographs and archaeology', American Antiquity, 2 (1936), 102-7; D. N. Riley, 'The technique of air archacology', Arcbaeol. J., ror (1944), 1-16; R. S. Solecki, 'Practical aerial photography for archaeologists', American Antiquity, 22 (1957), 337-5I; J. K. S. St Joseph, 'Air photography and archaeology', Geogr. J., Ios (1945), 47-6r. 
is therefore very useful for detecting shadow sites, in as much as such features of low relief are best photographed under a low sun, ${ }^{5}$ when haze may often be a limiting factor on the success of the photography. A second major advantage of infrared films for the detection of shadow marks is that, since the shorter wavelengths have been cut off by filters, there is a much stronger shadow effect than obtained by panchromatic film because at the longer wavelengths there is less scattering of light and therefore poor shadow penetration. This is a most useful characteristic for enhancing micro-relief features such as shadow sites. Other properties of infrared film are discussed below.

Large scale vertical stereo photography can also be very useful for studying shadow sites, as the large vertical exaggeration obtained by viewing two photographs in 3-D under a stereoscope can make objects of very subdued relief appear higher and with steeper sides.

Two other types of directly visible marks which emphasize small changes in relief have been recognized in photographing sites of archaeological significance, namely snow marks and flood marks. Snow marks may occur when a thin covering of windblown snow or hoar-frost collects in minor depressions on the ground surface, producing distinct tonal contrasts. Such marks may also be produced by differential melting of a complete covering of snow. Features of low relief may also be enhanced by flooding. When a river floodplain is submerged and the water reaches a certain level, minor topographical variations will be emphasized by the contrast between dry land and water. Snow marks and flood marks indicate the ephemeral nature of archaeological site detection. These marks are too rare to be of much practical use, due to the small chance of obtaining suitable weather conditions.

This leads one to consider those archaeological sites that are not clearly visible, having been either buried or ploughed down. Their recognition on the surface depends on some medium such as soil or vegetation, both rather variable environmental factors, so that each photograph is almost a unique case, in that it is difficult to repeat the results. As with snow and flood marks, the element of chance involved in obtaining suitable pictures is still rather large.

The various characteristics of soil marks and crop marks as used for the detection of sites has been described in the literature, ${ }^{6}$ so that only some of the effects of soil and vegetation which produce distinctive tonal patterns on aerial photographs need be considered here. Some of the main properties of soil which need to be taken into account are soil depth, soil colour, soil texture and soil moisture. Soil texture is not only important for the identification of a site; its likely agricultural potential in the past needs to be considered also. Soil moisture is, in fact, the main property of the terrain used for both the detection of soil marks and crop marks, as it is variation in the water content of the soil which will be reflected by different tones in areas of bare soil, and by differences in the quality, colour, height, density, and stage of growth in cultivated or vegetated areas. Again, most of the work to date had been mainly concerned with attempting to detect such sites using black and white panchromatic film.

5 R. J. Hackman, 'Time, shadows, terrain and photo interpretation', U.S. Geograpbical Survey, Professional Papers, 575 B (1967), $155-60$.
6 H. L. Cameron, 'History from the air', Pbotogrammetric Engineering, 24 (1958), 266-75; Riley, op. cit.; R. S. Solecki, et al., op. cit. in n. 2. 
In contrast to black and white film, where grey tones provide the basic means for separating objects, colour film offers two extra dimensions of hue and chroma (strength of colour). Photo interpreters are accustomed to identifying features not only on the basis of shape or form but also colour. ${ }^{7}$ Humans can separate many more combinations of hue and chroma than grey tones $(2,000: 20)$.

Infrared films, both black and white and false colour, offer two important properties in addition to those obtainable by black and white panchromatic and ordinary colour film. Firstly, as water readily absorbs infrared radiation, areas with different soil moisture contents are easily detected, thus enhancing the likelihood of locating soil marks. This effect holds for areas with a vegetation cover, and thus infrared films are also of value for detecting crop marks. The second characteristic of infrared films is the fact that with vegetation, reflection is strongest in the near infrared. This is indicated in Fig. 2, which shows that the reflectance spectrum of green plants ranges in value from slightly more than $5 \%$ at 0.6 microns to approximately $45 \%$ at 0.75 microns. Also, this region of the spectrum contains a pronounced chlorophyll absorption band, and is therefore very sensitive to changes in the health of green plants. Because of this, infrared films have been shown to be very useful for detecting physiological stress in plants due to a lack of water, or to an impediment in root penetration (as in negative crop marks) or an

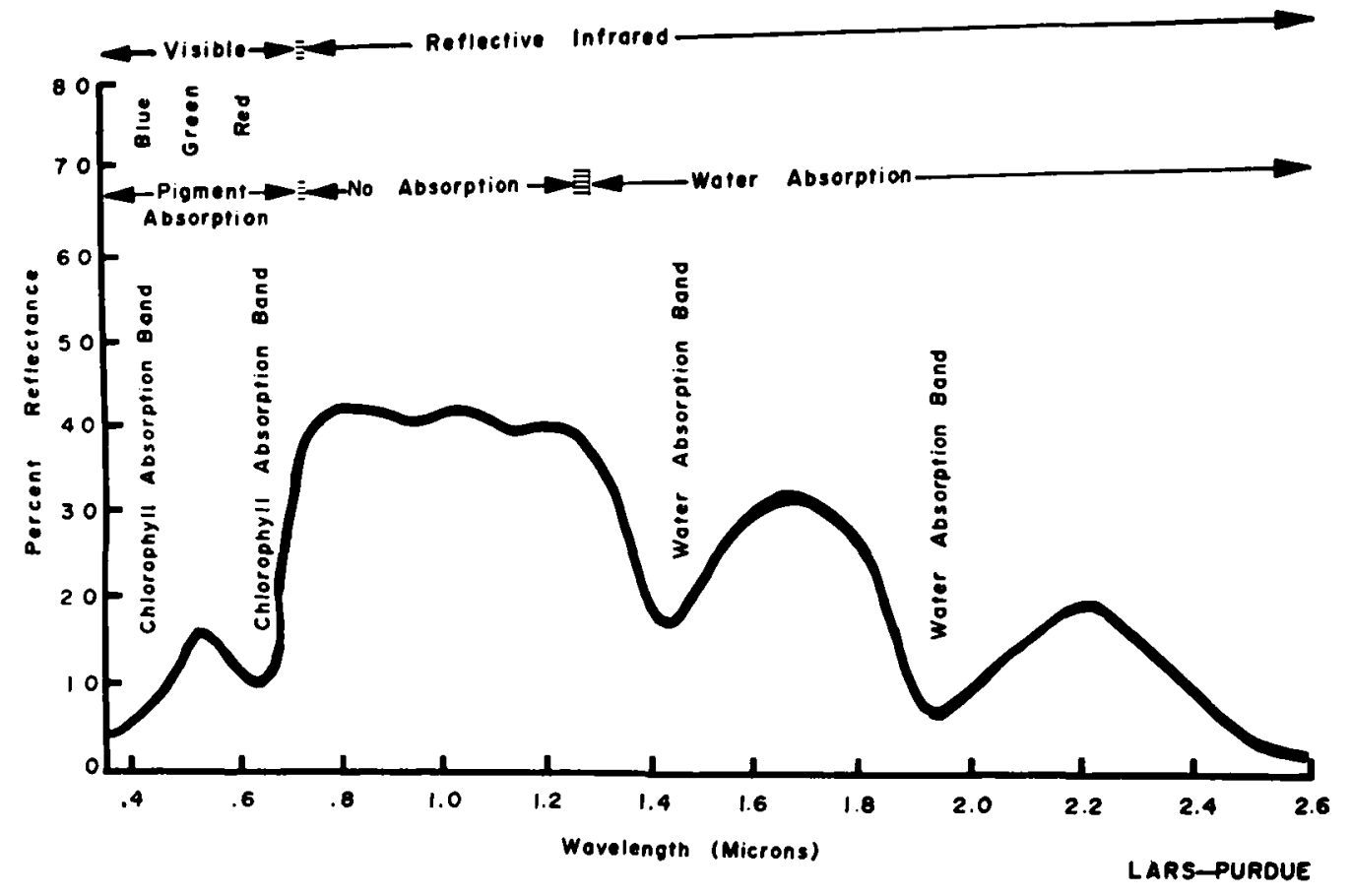

Fig. 2. Characteristic spectral reflectance curve of a green leaf

7 B. Edeine, 'Une méthode pratique pour la détection aérienne des sites archéologiques, en particulier par la photographie sur films en couleurs et sur films infrarouges', Bulletin de la Société Prébistorique Franfaise, 53 (1956), 540-6. 
overdeveloped root system (as with positive crop marks). The problems of angle of photography, time of day, season of year, local weather conditions preceding and during the taking of the photographs etc., must still to be taken into account, ${ }^{8}$ but with infrared films the likelihood of a successful flight is greatly increased.

What becomes apparent from the work carried out using black and white panchromatic, black and white infrared, colour, and false colour films, is that certain features are better detected on one film type than on another. This has led to the development of the multiband approach to site analysis. The basic concept behind multiband reconnaissance is that by comparing two or more photographs of the same area taken at the same time but made in different regions of the electro-magnetic spectrum, one can learn something about an object which one could not learn by studying the tonal values on just one photograph. Strandberg gives a good example of this in his study, ${ }^{9}$ where, on black and white panchromatic photography, circular house pits were indistinguishable from circular marks indicating the former location of haystacks, whilst on infrared film, these two features were strikingly different in tone, thereby facilitating more accurate interpretation.

One other remote sensing technique which may warrant further investigation is the use of thermal infrared imagery. Schaber and Gumerman have already given some archaeological applications of this technique, which will certainly provide information about sites at some depth, not normally recorded on standard aerial photographs. ${ }^{10}$

This trend towards using images taken outside the visual portion of the spectrum is one that needs to be further explored, especially now that modern agricultural practices are destroying many sites. Many recent photographs either do not show sites or show them only faintly, in areas where, on photographs taken thirty years ago, they are vividly clear. This is due to both deeper ploughing techniques destroying soil marks, and newer varieties of agricultural crops such as cereals which are now shorter, and therefore have a lesser root penetration depth, so that they do not reflect subsurface archaeological sites as easily as was the case with the former taller varieties with their larger and deeper root systems. Hence increasing use should be made of infrared films which enable one to record soil moisture differences as indicated in both soil and crop marks, where these are no longer visible on conventional black and white panchromatic photographs.

Even if the film type, filter, time of day, season of year, flying height, focal length, angle of view, etc., are all correct, there still remains the urgent need for field work to substantiate the photo interpretation. Many air archaeologists spend much time in procuring vast quantities of aerial photographs of sites without having set foot in the field to determine what it is they have recorded and, perhaps more important, why it is that a site has been recorded. If the latter was undertaken more frequently, further advances might be made in designing the optimum operational parameters such as

8. Martin, 'Archaeological sites - soils and climate', Pbotogrammetric Engineering, 37 (1971), $353-7$.

C. H. Strandberg, 'Photo-archaeology', Pbotogrammetric Engineering, 33 (1967), I I $2-7$.
10 C. G. Schaber and G. S. Gumerman, 'Infrared scanning images: an archacological application', Science, 164 (1969), $712-13$. 
film/filter, flight and time. ${ }^{11}$ An integrated programme is required, involving field work as well as both vertical and oblique photography using a variety of film/filter combinations, so that both the site and the environmental conditions can be evaluated and interpreted. ${ }^{12}$ Such a programme would overcome many of the present problems where interpretation is often hampered by a lack of knowledge of the various conditions obtaining at the time of photography, and lack of field control to substantiate the aerial photographic data. ${ }^{13}$

The advances made in many other disciplines in the understanding and utilization of images in various parts of the electro-magnetic spectrum, have not yet been exploited to any great extent by archaeologists, many of whom are still using procedures devised over thirty years ago. However, it should always be borne in mind that aerial photographs provide only one source of data, which should be considered along with other forms such as documentary evidence, field work, maps, etc. There is the need, first of all, to have particular problems which require an answer, or hypotheses regarding, for example, early settlements and agricultural systems, which need testing. Once these have been refined and clarified, then remote sensing techniques in archaeology may rapidly improve.

Submitted in 1974

$11 \mathrm{Y}$. Kedar, "The use of aerial photographs in research in physio-geographic conditions and anthropogeographic data in various historic periods', Photogrammetric Engineering, 24 (1958), 584-7; W. C. Miller, 'Uses of aerial photographs in archaeological field work', American Antiquity, 23 (1957), 46-62.
${ }^{12} \mathrm{~K}$. W. Butzer, Environment and Arcbaeology (London, 1964).

$13 \mathrm{~J}$. N. Hampton, "An experiment in multispectral air photography for archaeological research', Photogrammetric Record, 8 (1974), $37-63$. 